Preliminary Effects of Conditioned Establishing Operations on Stereotypy

\author{
Marc J. Lanovaz \\ Université de Montréal \\ John T. Rapp \\ St. Cloud State University \\ Ethan S. Long \\ The Virginia Institute of Autism \\ Sarah M. Richling \\ University of Nevada-Reno \\ Regina A. Carroll \\ West Virginia University
}

\begin{abstract}
Author Note
Portions of this project were supported by a grant provided to the second and third
\end{abstract} authors by Autism Speaks \#2852. Correspondence concerning this article should be addressed to Marc J. Lanovaz, École de Psychoéducation, Université de Montréal, C.P. 6128, succ. CentreVille, Montreal, QC, H3C 3J7, Canada. Tel.: 1 514-343-6111 ext. 81774. Email:

marc.lanovaz@umontreal.ca

This is a post-peer-review, pre-copyedit version of an article published in The Psychological Record. The final authenticated version is available online at: https://doi.org/10.1007/s40732$\underline{014-0027-\mathrm{X}}$ 


\begin{abstract}
We repeatedly paired preferred stimuli with known establishing properties and poster boards (i.e., neutral stimuli) to examine whether these poster boards would acquire the effects of a conditioned establishing operation in five children with autism. Following pairing, the poster boards, which had been previously shown to be neutral, increased immediate or subsequent engagement in stereotypy for 3 of 5 participants. The results suggest that it is possible to condition establishing operations for stereotypy and that this process may occur inadvertently. We discuss the potential clinical implications of the results as well as the need for future research to replicate our findings.
\end{abstract}

Keywords: autism, automatic reinforcement, establishing operation, conditioned motivating operation, stereotypy 


\section{Preliminary Effects of Conditioned Establishing Operations on Stereotypy}

Motivating operations (MOs) are antecedent events that alter both the value of a consequence and the frequency of responses associated with the consequence (Laraway, Snycerski, Michael, \& Poling, 2003). Laraway et al. (2003) differentiated between two types of MOs: the establishing operation (EO), which increases the value of a given consequent event, and the abolishing operation (AO), which decreases the value of a consequent event. When the consequent event is a reinforcer, EOs increase and AOs decrease engagement in behavior maintained by the consequent event. Conversely, EOs and AOs that alter the value of punishers will produce the opposite effect on behavior. Furthermore, a MO can be either unconditioned or conditioned (McGill, 1999; Michael, 1993). Unconditioned motivating operations (UMOs) are not the result of an individual's learning history. In contrast, conditioned motivating operations (CMOs) acquire their properties through learning.

Michael (1993) described three types of CMOs, which are each conditioned in a different manner. First, the surrogate $\mathrm{CMO}$ acquires its motivating properties through temporal correlation with a stimulus event with known MO effects (i.e., a UMO or another CMO). For example, a stimulus that is historically correlated with deprivation (i.e., a known UEO) may evoke behavior and increase the value of a consequent event in the same manner as deprivation. Adelinis, Piazza, Fisher, and Hanley (1997) observed that a person with a disability engaged in higher levels of attention-maintained self-injury when in her wheelchair. In a subsequent discussion paper, McGill (1999) hypothesized that the wheelchair may have been historically correlated with deprivation and may thus have functioned as a surrogate CEO for self-injury.

Second, the reflexive CMO acquires its properties by being temporally correlated with improvement or worsening. Assume that (a) a warning stimulus systematically precedes an aversive event, (b) the warning stimulus can be terminated by a response which occurs more 
frequently in the presence of the stimulus, and (c) the termination of the warning stimulus prevents the aversive event. In this case, the warning stimulus would be a reflexive CEO because its occurrence does not signal the availability of a consequence, but rather increases the value of the response that produces its interruption (Michael, 1993). The presentation of academic materials may function as a reflexive $\mathrm{CEO}$ when an inappropriate behavior leads to the removal of the materials and the avoidance of the task at hand (Shillingsburg, 2005). Finally, the transitive $\mathrm{CMO}$ acquires its properties by altering the value of another stimulus event and engagement in the behavior associated with the latter. In a study on derived responding, Rosales and Rehfeldt (2007) contrived transitive CEOs by making objects necessary to complete chained tasks accessible only through manding. The context (i.e., inaccessibility of the item to complete the chain) functioned as a transitive CEO by increasing the reinforcing value of the item and the frequency of the behavior (i.e., manding) to access the item.

In the case of behaviors maintained by nonsocial or automatic reinforcement, behavior changes are inextricably linked to MOs (Rapp, 2008). That is, changes in levels of automatically reinforced behavior observed in the absence of social consequences are generally conceptualized in terms of changes in motivation to engage in the behavior. Given that the stimulation that maintains the behavior is always available, changes in automatically reinforced behavior under free-operant conditions cannot be attributed to stimulus control, which signals the availability of a consequence. Instead, increased engagement under free-operant conditions typically indicates that an EO is present for engaging in non-socially reinforced behavior whereas decreased engagement suggests that an AO is present (e.g., Friman, 2000; Lang et al., 2009, 2010; Rapp, 2004, 2007; Van Camp et al., 2000). Based on Michael's conceptualizing of CMOs, pairing these AOs and EOs with other stimuli may condition novel surrogate CMOs. Given that the environments in which these MOs occur often contain a large number of neutral stimuli, 
surrogate CMOs may sometimes be conditioned through inadvertent pairing between a stimulus and a naturally occurring MO. As such, research is necessary to further advance our understanding of CMOs, but also to examine whether these processes may have clinical implications.

To our knowledge, no study had previously examined the possibility of conditioning a surrogate CMO for automatically reinforced behavior emitted by children with autism. Translational research examining the processes by which CMOs acquire their properties in children with autism may have the potential to benefit both the experimental and applied sciences of behavior analysis (Critchfield, 2011; Lerman, 2003). From an experimental standpoint, investigating of how neutral stimuli become CMOs may advance our basic understanding of behavior change. From a clinical standpoint, examining whether repeatedly pairing an event with known MO properties and a neutral stimulus produces a CMO may be important because these processes probably occur inadvertently in applied settings. Eventually, the results of such experiments may give rise to novel interventions that make use of these basic principles to change behavior in a meaningful way.

In terms of EOs for automatically reinforced behavior, the literature suggests that such behavior can be increased by either (a) restricting access to the behavior for a period of time (e.g., Rapp, 2007; Rapp, Vollmer, St. Peter, Dozier, \& Cotnoir, 2004), or (b) providing access to a specific stimulus (Carter, Devlin, Doggett, Harber, \& Barr, 2004; Friman, 2000; Piazza, Adelinis, Hanley, Goh, \& Delia, 2000; Rapp, 2004, 2005; Van Camp et al., 2000). Based on the findings from these studies, there may be two ways to condition an EO for automatically reinforced behavior. First, a neutral stimulus could be repeatedly paired with conditions of high deprivation from sensory stimulation, thereby acquiring properties of a surrogate CEO. Alternatively, a neutral stimulus could be repeatedly paired with another stimulus, which has 
been shown to produce an EO. Given that McGill (1999) speculated that it may be easier to condition EOs from motivational events that change rapidly than from events that change slowly (e.g., food deprivation), we opted to evaluate the extent to which we could generate a CEO through pairing with a specific stimulus event (e.g., music), which was shown to increase stereotypy. Although there may not be any direct clinical benefits to conditioning EOs for stereotypy, a CEO could be inadvertently produced in clinical settings. Thus, it is important to understand the conditions that may give rise to such conditioning. The purpose of the current study was to examine whether neutral stimuli could acquire evocative properties for automatically reinforced behavior through pairing with stimulus events with known EO effects.

\section{Method}

\section{Participants and Settings}

The participants were five children with autism aged between 7 and 9 years old. Each child had previously participated in a study on the effects of preferred stimuli on engagement in vocal and motor stereotypy (Rapp et al., 2012). We selected these children because each showed either immediate or subsequent increases in one or more forms of motor stereotypy during preferred stimulation. These patterns indicated that preferred stimulation produced an EO for engagement in motor stereotypy.

\section{Data Collection and Interobserver Agreement}

Trained graduate students scored video recordings of the sessions for the duration of motor stereotypy using computers equipped with a real-time data collection program. Table 1 presents the target behaviors and their definitions for each participant. Duration events were converted to a percentage of time measure by dividing the number of seconds engaged in an event by the total number of seconds in a session and then multiplying by $100 \%$. Interobserver agreement (IOA) scores were calculated by using the block-by-block method with 10-s intervals 
(see Mudford, Taylor, \& Martin, 2009). A secondary observer scored 33\%, 33\%, 36\%, 31\%, and $35 \%$ of the sessions for Mason, Jared, Oliver, Fred, and Peter, respectively. Mean IOA scores for Mason's hand flapping and body rocking were 94\% (range, 87\%-97\%) and 92\% (range, 89\%94\%), respectively. The mean IOA score for Jared's body rocking was 95\% (range, 88\%-99\%). Mean IOA scores for Oliver's hand flapping and finger movements were 95\% (range, 92\%-98\%) and $94 \%$ (range, 90\%-96\%), respectively. The mean IOA score for Fred's hand tapping was 92\% (range, $88 \%-96 \%$ ). Mean IOA scores for Peter's finger movements and ear covering were $94 \%$ (range, $89 \%-98 \%$ ) and 93\% (range, 92\%-95\%), respectively.

\section{Experimental Design and Procedures}

We divided 30-min sessions into three equal-duration components and used multielement designs to determine the extent to which a neutral stimulus (i.e., colored poster boards) could acquire the properties of a CEO for stereotypy. As such, each sequence was composed of three 10-min components. To examine whether the previously neutral stimulus had acquired the properties of a CEO, we first conducted one or two probes to ensure that the poster boards did not exert an effect on motor stereotypy prior to conditioning. Next, we compared levels of motor stereotypy in the presence and absence of the poster boards within a multielement design. On the days preceding each test session (i.e., in the presence of poster boards), we conducted a series of pairing sessions during which we correlated the poster boards with a preferred stimulus with known EO effects.

No-interaction (NI) sequence. The three components of the NI sequence were always the same. A trainer was present in the room with the participant but she did not provide social consequences for any of the participant's behavior. Furthermore, the participants did not have access to play or work materials during the sequence. The purpose of this sequence was to 
examine whether the behavior persisted in the absence of social consequences and serve as a baseline against which the effects of the CEO could be evaluated.

Pre-CEO probe sequence. Pre-CEO probe sequences consisted of three, 10-min components conducted in the same manner as the NI sequence except that we taped colored poster boards $(0.6 \mathrm{~m}$ by $0.7 \mathrm{~m})$ to three walls for the duration of the component (i.e., during either the first or the second component) wherein we planned to provide the CEO after conducting pairing sessions. The purpose of the probe sequence was to determine if the presence of the colored poster boards exerted any effects on participants' stereotypy prior to conditioning.

Pairing sessions. The pairing sessions were $10 \mathrm{~min}$ in duration. During these sessions, a trainer provided continuous access to the preferred stimuli that were used in the Rapp et al. (2012) study. That is, we provided continuous access to music to Mason, Jared, Oliver and Peter, and continuous access to a slinky to Fred. As in the Pre-CEO sequence, we taped colored poster boards (i.e., the neutral stimulus) to three of the walls in the session room either during the last 2 min of the 10-min session or during the entire 10-min session (Jared only). We paired the poster boards with the last 2 min of each session because we hypothesized that the value of the targeted stereotypy was at its highest towards the end of the session. Only Jared was exposed to the poster boards for the entire 10-min session because we implemented the change after he had begun his participation in the study. Two to six pairing sessions $(M=3.6)$ were conducted before each CEO-Test sequence, and one or two pairing sessions were conducted per day. We always conducted pairing sessions the day before a CEO-Test, but we never conducted pairing sessions on the same day as a test sequence.

CEO-Test sequence. The CEO-Test sequence consisted of three, 10-min components. During either the first or second components of the CEO-Test sequence, the trainer taped the poster boards, which were previously paired with the preferred stimulus, on three of the walls in 
the session room. The poster boards were presented during the entire component; however, the trainer did not provide access to the preferred stimulus. If the poster boards were presented in the second component (Jared, Mason, and Fred), then the first and third components were identical to the components used in the NI sequence. If the poster boards were presented in the first component (Oliver and Peter only), then the second and third components were identical to the components used in the NI sequence. We opted to provide the CEO in the first component for Oliver and Peter because they exhibited increases in stereotypy following the withdrawal of preferred stimulation (Rapp et al., 2012). Thus, providing the poster boards in the first component allowed us to use the second and third components to evaluate the subsequent effects on stereotypy. Poster boards were not accessible to the participants outside of the pairing and test sessions (i.e., the poster boards were kept in a locked drawer or closet). The purpose of the CEOTest sequence was to evaluate the extent to which the poster boards acquired properties of a CEO as indicated by (a) increased stereotypy when they were present, or (b) increased stereotypy after they were removed.

\section{Results}

Table 2 provides a summary of the results for each participant's stereotypy during the NI and CEO-Test sequences. For each participant, engagement in stereotypy during the Pre-CEO probe sequences (data available from second author) was comparable to levels of responding observed during the NI sequences. This finding suggests that the poster boards functioned as a neutral stimulus prior to the pairing sessions. A visual analysis of the results indicated that the poster boards increased immediate or subsequent engagement in stereotypy (i.e., produced an immediate or subsequent CEO) for three of the five participants. These results are depicted in Figures 1 and 2. It is important to note that mean differences between sequences were sometimes similar for the remaining two participants, but that a visual analysis of the results 
indicated that the paths were undifferentiated and the apparent differences in means were largely due to outliers (data available from second author).

The upper panels of Figure 1 show the percentage of time Mason engaged in hand flapping during the first (left column), second (middle column), and third (right column) components of the Pre-CEO probe, NI, and CEO-Test sequences. During the first components, engagement in hand flapping remained similar regardless of the sequence. The results for the second components show that Mason's hand flapping was higher during the CEO-Test sequences (i.e., when the poster boards were present) than during the NI sequences (i.e., when the poster boards were absent); however, the data paths for the third components were undifferentiated. The results suggest that the poster boards produced an immediate increase in Mason's hand flapping, but did not alter his subsequent engagement in the behavior. The middle panels of Figure 1 show the percentage of time Mason engaged in jumping. The results for the first and second components show that Mason's jumping was undifferentiated across the NI and CEO-Test sequences. Nonetheless, Mason's jumping in the third components was higher during the CEOTest sequences than during the NI sequences, suggesting that the poster boards increased subsequent engagement in jumping.

The lower panels of Figure 1 show the percentage of time Jared engaged in body rocking across the Pre-CEO probe, NI, and CEO-Test sequences. Although the data paths were undifferentiated during the first components, engagement in body rocking was on average higher in the NI than in the CEO-Test sequences. The results for the second and third components show that Jared's body rocking was also generally higher during the CEO-Test sequences than during the NI sequences. Given that levels of body rocking were already higher in the CEO-Test sequences prior to the introduction of the poster boards, it is difficult to attribute the changes observed in the second and third components to the independent variable. Lanovaz, Rapp, and 
Fletcher (2010) proposed a methodology to analyze data from the three-component multipleschedule, which controls for differences observed prior to the introduction of the independent variable. The within-sequence analysis involves using the first component as a control against which the other two components are compared. Levels of body rocking were never higher in the second components than in the first components during NI sequences. In contrast, engagement in body rocking was higher in the second components than in the first components for $33 \%$ of CEO-Test sequences, suggesting that the poster boards produced marginal immediate increases in the target behavior relative to baseline. However, body rocking was higher in the third components than in the first components for the same number of sessions (i.e., 1) for both the NI and CEO-Test sequences. Thus, the subsequent effects of the poster boards on Jared's body rocking remained inconclusive.

Figure 2 shows the percentage of time Oliver engaged in hand flapping during the first (left panel), second (middle panel), and third (right panel) components of the Pre-CEO probe, NI, and CEO-Test sequences. The results for the first components (i.e., when the poster boards were present) show that Oliver's hand flapping was undifferentiated during the CEO-Test and NI sequences. The results for the second components show that Oliver's hand flapping was higher in the CEO-Test sequences than during the NI sequences; however, during the third components Oliver's hand flapping was again undifferentiated during the CEO-Test and NI sequences. These results indicate that the poster boards produced a subsequent increase in Oliver's hand flapping in the second components of the CEO-Test sequences, but this increase did not extend into the third components.

\section{Discussion}

Overall, the experiment shows that the presence of poster boards, which were repeatedly paired with stimulus events with known EO effects, altered engagement in stereotypy for three of 
five participants. By examining the processes underlying the conditioning of CEOs with a socially significant behavior in a clinical population, we conducted a translational study that not only informs researchers about the basic principles of behavior, but also provides potential avenues for research on the assessment and treatment of stereotypy. The neutral stimulus acquired the properties of a CEO for some forms of stereotypy. Specifically, we hypothesize that presentation of the poster boards during the second components of the CEO-Test sequence increased the value of and evoked engagement in hand flapping for Mason and body rocking for Jared. These results were consistent with the results of Rapp et al. (2012), which showed that access to a preferred stimulus in the second components functioned as an immediate EO for Mason's hand flapping and Jared's body rocking. Similarly, the removal of the poster boards produced an increase in hand flapping for Oliver similar to the increase observed when the preferred stimuli were removed in the Rapp et al. study. The results are generally consistent with the concepts proposed by Michael (1993). That is, repeatedly pairing an observable event (i.e., preferred stimulation) that produces an EO with a neutral stimulus may condition a surrogate CEO. Some prior studies have contrived transitive CEOs to teach communication (e.g., Rosales \& Rehfeldt, 2007), but to our knowledge, this may be the first study to demonstrate the effects of a surrogate $\mathrm{CEO}$ on automatically reinforced behavior.

There are at least two alternative accounts for the immediate and subsequent increases in stereotypy that were observed in the study. First, stereotypy may have been elicited by the presentation of the preferred stimulus during the pairing sessions. In this way, the behavior displayed by each participant may have been respondent, as opposed to operant, and the preferred stimulus may have functioned as an unconditioned stimulus (US). In keeping with this account, the poster boards may have become a conditioned stimulus (CS), thereby eliciting stereotypy during CEO-Test sessions. However, this alternative account is unlikely for at least 
two reasons. First, participants engaged in stereotypy during all three components of the NI sequence. If stereotypy was indeed a respondent behavior, we would not expect stereotypy to occur in the absence of a US or CS. Second, prior studies have shown that automatically reinforced behavior, which increased in the presence of a preferred stimulus, was modified by consequences (Rapp, 2005; Van Camp et al., 2000). For example, Rapp (2005) found that noncontingent access to TV (i.e., auditory and visual stimulation) increased a participant's body rocking relative to a baseline condition. Following the introduction of a brief time out from TV contingent on the body rocking, the participant's engagement in body rocking decreased, but his engagement in other forms of stereotypy increased. This finding suggests that body rocking was operant behavior even though it was emitted when a specific type of stimulation was present.

It is also possible that the poster boards functioned as a discriminative stimulus $\left(\mathrm{S}^{\mathrm{D}}\right)$, signaling the availability of the preferred stimulus. In this way, the participants' engagement in stereotypy could be conceptualized as a behavior maintained by socially-mediated reinforcement evoked by the presentation of the poster boards (i.e., a $\mathrm{S}^{\mathrm{D}}$ ). However, this account also seems unlikely because we did not provide contingent access to the preferred stimulus during either the pairing or test sessions. Instead, we provided continuous, noncontingent access to the preferred item during the pairing sessions. Put differently, there was never a contingency between engaging in stereotypy and receiving access to the preferred stimulus in the presence or absence of the poster boards. In addition, if the poster boards did function as a $\mathrm{S}^{\mathrm{D}}$ for the availability of the preferred stimulus for engaging in stereotypy, we would not expect to see stereotypy increase after the poster boards were removed. Thus, it seems more likely that the poster boards functioned as a CEO that evoked and increased the value of the stimulation generated by stereotypy. 
The results of the investigation should be viewed as preliminary and translational, but the findings may still give rise to important clinical implications. Practitioners may inadvertently condition EOs for stereotypy. For example, assume that a trainer works with a child who often engages in vocal stereotypy during instructional segments. Following compliant responding on a specified number of trials, the trainer provides access to music, which is matched to vocal stereotypy and preferred by the child, during a break period. Even though the child engages in high levels of body rocking while the music is playing, the trainer continues to provide music during the break period because the child does not exhibit vocal stereotypy. Nevertheless, the effects of the music as an EO for body rocking may persist after the break period such that the child body rocks during the next few minutes of instruction instead of engaging in the designated task. Furthermore, if particular items (e.g., a CD player) are consistently visible when music is provided, the sight of the item may function as a CEO, increasing the child's body rocking, which may compete with his engagement in academic tasks. In short, preventing the subsequent effects of EOs and the immediate and subsequent effects of CEOs may be important for reducing automatically reinforced behavior as well as decreasing socially reinforced problem behavior (McGill, 1999). Replicating the procedures with socially reinforced behavior may possibly identify mechanisms through which some stimuli acquire EO properties in the natural environment. A better understanding of the mechanisms through which CMOs acquire their properties may also improve currently available treatments as well as provide an explanation for some observed variability that remains unaccounted for in applied settings.

There are some potential limitations to the present study that should be discussed. We were only able to condition an EO for three of the five participants who exhibited increased stereotypy in the presence of their preferred stimulus. Furthermore, some of the behavior changes produced by the poster boards were relatively small and variable. The mechanisms that may 
explain these inconsistencies should be investigated in the future. For example, participants may have habituated to the presence of the poster boards after repeated or extended presentations of the stimulus. In addition, caregivers may have provided access to the preferred stimulus outside of the assessment sessions; such access could constitute an "unpairing" between the poster boards and the preferred stimulus. Thus, incorporating stimuli that are resistant to habituation (e.g., blinking signs) and controlling access to the preferred stimulus outside of sessions may produce a stronger CEO. Moreover, the persistence of each form of stereotypy suggests that the target behaviors were at least partly automatically reinforced, but the lack of functional analysis does not allow us to rule out other functions. Researchers should consider conducting a complete functional analysis in the future to address this concern.

The refinement of technologies to assess and manipulate MOs related to automatically reinforced behavior may assist practitioners in the development of effective and enduring treatments. Thus, the results of the present study support several areas for future research on evaluating the effects of CMOs on automatically reinforced behavior. In the present study, we paired a neutral stimulus with access to one preferred stimulus; future research should evaluate the extent to which pairing a neutral stimulus with multiple items would enhance the effects of conditioning a MO for automatically reinforced behavior. To determine the generality and reliability of the effects described in this study, researchers should first conduct direct and systematic replications of CMO conditioning procedures with socially and non-socially reinforced behavior. Future research could also evaluate the effects of presenting a CMO for automatically reinforced behavior on other socially reinforced behavior. For example, the presence of a CEO for automatically reinforced behavior may also alter the value of social reinforcers (e.g., attention) delivered contingent on appropriate behavior. Future research should also continue to evaluate the optimal method for conditioning MOs for automatically reinforced 
behavior. Finally, researchers may evaluate the extent to which similar procedures could condition a CAO for stereotypy, which may have potential clinically utility for treating automatically reinforced problem behavior. 


\section{References}

Adelinis, J. D., Piazza, C. C., Fisher, W. W., \& Hanley, G. P. (1997). The establishing effects of client location on self-injurious behavior. Research in Developmental Disabilities, 18, 383-391. doi:10.1016/S0891-4222(97)00017-6

Carter, S. L., Devlin, S. R., Doggett, A., Harber, M. M., \& Barr, C. (2004). Determining the influence of tangible items on screaming and handmouthing following an inconclusive functional analysis. Behavioral Interventions, 19, 51-58. doi: 10.1002/bin.150

Critchfield, T. S. (2011). Translational contributions of the experimental analysis of behavior. The Behavior Analyst, 34, 3-17.

Friman, P. C. (2000). "Transitional objects" as establishing operations for thumb sucking: A case study. Journal of Applied Behavior Analysis, 33, 507-509. doi:10.1901/jaba.2000.33-507

Lang, R., O’Reilly, M., Sigafoos, J., Lancioni, G. E., Machalicek, W., Rispoli, M., \& White, P. (2009). Enhancing the effectiveness of a play intervention by abolishing the reinforcing value of automatically reinforced behavior: A pilot study. Journal of Applied Behavior Analysis, 42, 889-894. doi:10.1901/jaba.2009.42-889

Lang, R., O’Reilly, M., Sigafoos, J., Machalicek, W., Rispoli, M., Lancioni, G. E.... Fragale, C., (2010). The effects of an abolishing operation intervention component on play skills, challenging behavior, and automatically reinforced behavior. Behavior Modification, 34, 267-289. doi:10.1177/0145445510370713

Lanovaz, M. J., Rapp, J. T., \& Fletcher, S. E. (2010). Expanding functional analysis of automatically reinforced behavior using a three-component multiple-schedule. European Journal of Behavior Analysis, 11, 17-27. 
Laraway, S., Snycerski, S., Michael, J., \& Poling, A. (2003). Motivating operations and terms to describe them: Some further refinements. Journal of Applied Behavior Analysis, 36, 407414. doi:10.1901/jaba.2003.36-407

Lerman, D. C. (2003). From the laboratory to community application: Transitional research in behavior analysis. Journal of Applied Behavior Analysis, 36, 415-419. doi:10.1901/jaba.2003.36-415

McGill, P. (1999). Establishing operations: Implications for the assessment, treatment, and prevention of problem behavior. Journal of Applied Behavior Analysis, 32, 393-418. doi:10.1901/jaba.1999.32-393

Michael, J. (1993). Establishing operations. The Behavior Analyst, 16, 191-206.

Mudford, O. C., Taylor, S. A., \& Martin, N. T. (2009). Continuous recording and interobserver agreement algorithms reported in the Journal of Applied Behavior Analysis (1995-2005). Journal of Applied Behavior Analysis, 42, 165-169. doi:10.1901/jaba.2009.42-165

Piazza, C. C., Adelinis, J. D., Hanley, G. P., Goh, H., \& Delia, M. D. (2000). An evaluation of the effects of matched stimuli on behaviors maintained by automatic reinforcement. Journal of Applied Behavior Analysis, 33, 13-27. doi:10.1901/jaba.2000.33-13

Rapp, J. T. (2004). Effects of prior access and environmental enrichment on stereotypy. Behavioral Interventions, 19, 287-295. doi:10.1002/bin.166

Rapp, J. T. (2005). Some effects of audio and visual stimulation on multiple forms of stereotypy. Behavioral Interventions, 20, 255-272. doi:10.1002/bin.196

Rapp. J. T. (2007). Further evaluation of methods to identify matched stimulation. Journal of Applied Behavior Analysis, 40, 73-88. doi:10.1901/jaba.2007.142-05 
Rapp, J. T. (2008). Conjugate reinforcement: A brief review and suggestions for applications to the assessment of automatically reinforced behavior. Behavioral Interventions, 23, 113136. doi:10.1002/bin.259

Rapp, J. T., Vollmer, T. R., St. Peter, C., Dozier, C. L., \& Cotnoir, N. M. (2004). Analysis of response allocation in individuals with multiple forms of stereotyped behavior. Journal of Applied Behavior Analysis, 37, 481-501. doi:10.1901/jaba.2004.37-481

Rapp, J. T., Swanson, G., Sheridan, S., Enloe, K., Maltese, D., Sennott, L.,...Lanovaz, M. J. (2012). Immediate and subsequent effects of matched and unmatched stimuli on targeted vocal stereotypy and untargeted motor stereotypy. Behavior Modification. doi: $10.1177 / 0145445512461650$

Rosales, R., \& Rehfeldt, R. A. (2007). Contriving transitive conditioned establishing operations to establish derived manding skills in adults with severe developmental disabilities. Journal of Applied Behavior Analysis, 40, 105-121. doi:10.1901/jaba.2007.117-05

Shillingsburg, M. A. (2005). The use of the establishing operation in parent-child interaction therapies. Child \& Family Behavior Therapy, 26(4), 43-58. doi:10.1300/J019v26n04_03

Van Camp, C. M., Lerman, D. C., Kelley, M. E., Roane, H. S., Contrucci, S. A., \& Vorndran, C. M. (2000). Further analysis of idiosyncratic antecedent influences during the assessment and treatment of problem behavior. Journal of Applied Behavior Analysis, 33, 207-221. doi:10.1901/jaba.2000.33-207 
Table 1

Target Response Forms and Definitions for Each Participant

\begin{tabular}{|c|c|c|}
\hline Participant & Response form & Response definition \\
\hline \multirow[t]{2}{*}{ Mason } & Hand flapping & $\begin{array}{l}\text { Two or more up or down or side to side hand movements for } 2 \mathrm{~s} \\
\text { or more }\end{array}$ \\
\hline & Jumping & $\begin{array}{l}\text { Two or more instances of both feet leaving the ground for } 2 \mathrm{~s} \text { or } \\
\text { more }\end{array}$ \\
\hline Jared & Body rocking & $\begin{array}{l}\text { Two or more forward and backward torso movements for } 2 \mathrm{~s} \text { or } \\
\text { more }\end{array}$ \\
\hline \multirow[t]{2}{*}{ Oliver } & Hand flapping & $\begin{array}{l}\text { Two or more up or down or side to side hand movements for } 2 \mathrm{~s} \\
\text { or more }\end{array}$ \\
\hline & Finger moving & $\begin{array}{l}\text { Two or more front and backward movements of one or more } \\
\text { fingers for } 2 \mathrm{~s} \text { or more }\end{array}$ \\
\hline Fred & Hand tapping & $\begin{array}{l}\text { Two or more movements of the finger or hand for } 2 \mathrm{~s} \text { making } \\
\text { contact with a surface }\end{array}$ \\
\hline \multirow[t]{2}{*}{ Peter } & Finger moving & $\begin{array}{l}\text { Two or more front and backward movements of one or more } \\
\text { fingers for } 2 \mathrm{~s} \text { or more }\end{array}$ \\
\hline & Ear covering & Contact of one or both hand with one or both ears for $2 \mathrm{~s}$ or more \\
\hline
\end{tabular}


Table 2

Engagement in Motor Stereotypy Across No-Interaction and Conditioned Establishing Operation

Test Sequences

\begin{tabular}{|c|c|c|c|c|c|}
\hline \multirow[b]{2}{*}{ Participant } & \multicolumn{3}{|l|}{ Means } & \multirow[b]{2}{*}{$\begin{array}{l}\text { Immediate } \\
\text { Increase? }\end{array}$} & \multirow[b]{2}{*}{$\begin{array}{l}\text { Subsequent } \\
\text { Increase? }\end{array}$} \\
\hline & $\begin{array}{l}1^{\text {st }} \text { component } \\
\text { NI/CEO-T }\end{array}$ & $\begin{array}{l}2^{\text {nd }} \text { component } \\
\text { NI/CEO-T }\end{array}$ & $\begin{array}{l}3^{\text {rd }} \text { component } \\
\text { NI/CEO-T }\end{array}$ & & \\
\hline \multicolumn{6}{|l|}{ Mason } \\
\hline Hand flapping & $14 \% 12 \%$ & $13 \% / 22 \%$ & $12 \% / 10 \%$ & $\mathrm{Y}$ & $\mathrm{N}$ \\
\hline Jumping & $19 \% / 15 \%$ & $9 \% / \mathbf{1 0} \%$ & $5 \% / 10 \%$ & $\mathrm{~N}$ & $\mathrm{Y}$ \\
\hline \multicolumn{6}{|l|}{ Jared } \\
\hline Body rocking & $10 \% / 19 \%$ & $4 \% / \mathbf{1 5} \%$ & $3 \% / 10 \%$ & $\mathrm{Y}$ & $\mathrm{N}$ \\
\hline \multicolumn{6}{|l|}{ Oliver } \\
\hline Hand flapping & $17 \% / 13 \%$ & $10 \% / 37 \%$ & $8 \% / 15 \%$ & $\mathrm{~N}$ & $\mathrm{Y}$ \\
\hline Finger moving & $10 \% / 3 \%$ & $5 \% / 8 \%$ & $10 \% / 14 \%$ & $\mathrm{~N}$ & $\mathrm{~N}$ \\
\hline \multicolumn{6}{|l|}{ Fred } \\
\hline Hand tapping & $14 \% / 9 \%$ & $15 \% / \mathbf{1 0} \%$ & $16 \% / 8 \%$ & $\mathrm{~N}$ & $\mathrm{~N}$ \\
\hline \multicolumn{6}{|l|}{ Peter } \\
\hline Finger moving & $2 \% / 2 \%$ & $11 \% / 8 \%$ & $8 \% / 4 \%$ & $\mathrm{~N}$ & $\mathrm{~N}$ \\
\hline Ear covering & $16 \% / 29 \%$ & $8 \% / 17 \%$ & $15 \% / 16 \%$ & $\mathrm{~N}$ & $\mathrm{~N}$ \\
\hline
\end{tabular}

Note. Boldface denotes where the conditioned establishing operation $(\mathrm{CEO})$ was provided. $\mathrm{NI}=$ No-interaction sequence; $\mathrm{CEO}-\mathrm{T}=\mathrm{CEO}$-Test sequence. 


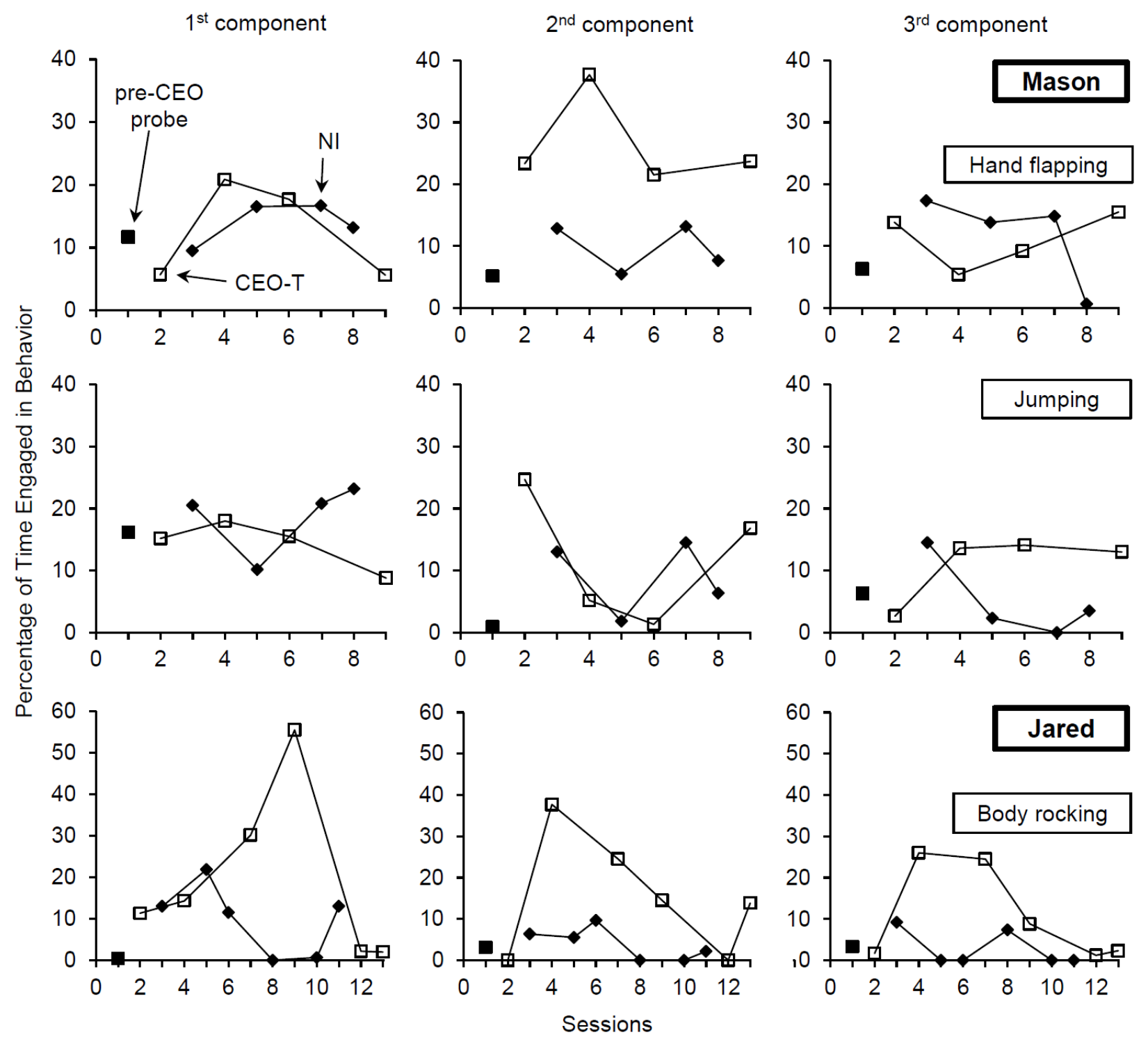

Figure 1. Percentage of time Mason (upper and middle panels) and Jared (lower panels) engaged in motor stereotypy during the first (left column), second (middle column), and third (right column) components of a pre-conditioned establishing operation (CEO) probe, no-interaction (NI), and CEO- Test (CEO-T) sequences. The CEO was provided in the second component only. 


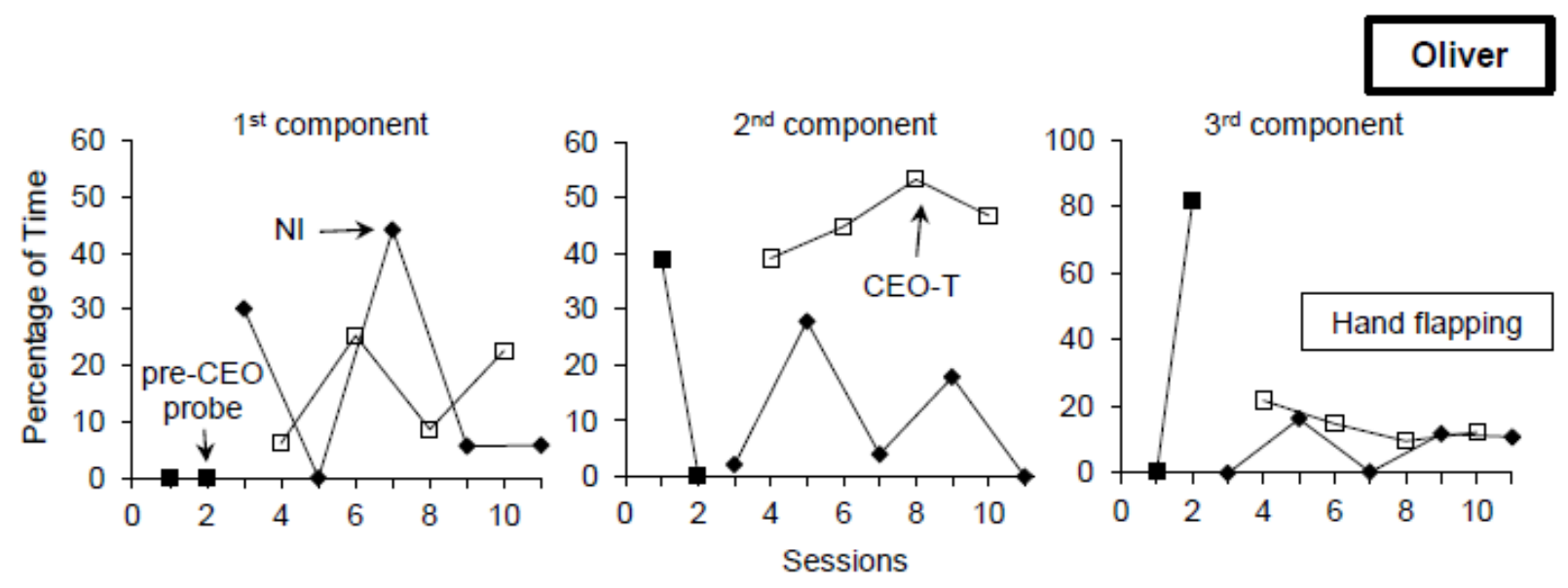

Figure 2. Percentage of time Oliver engaged in hand flapping during the first (right panel), second (middle panel) and third (left panel) components of pre-conditioned establishing operation (CEO) probe, no-interaction (NI), and CEO-Test (CEO-T) sequences. The CEO was provided in the first component only. Note that the y-scale of the right panel differs from the other panels due to the presence of an outlier. 